\title{
The Research and Practice on Construction of the Practical Course of Internet of Things
}

\author{
Jing Cai \\ Nanchang Institute of Science \& Technology, Nanchang, 330108, China
}

Keywords: Internet of things engineering, practical course

\begin{abstract}
Internet of things engineering is an emerging professional, It is still in the process of development at present, The purpose of this major is to train more students who are professional in the network, follow the tide of the times and contribute to the construction of the country. This paper analyzes the development of Internet of things and its training objectives and orientation, and puts forward some suggestions on the construction of practical courses of Internet of things.

The Internet of things was proposed by the Massachusetts institute of technology's automated identity center (MIT Auto-ID Center) in 1999. It means connecting objects with the Internet of things through sensors, GPS, laser scanning and other identification systems, so as to achieve intelligent recognition, tracking, location, management and so on. Prime Minister Wen Jiabao visited the Chinese Academy of Sciences in Wuxi in August 2009, who made a clear request for the establishment of the Chinese sensing information center, the center of "perception of China" as soon as possible. A large number of references to the Internet of things can make it easier to live in life and increase work efficiency. The arrival of the era of Internet of things has also challenged our development. The establishment of IOT engineering is to strengthen the competition of talents, train talents in this field, and also the future development of Internet of things in China.
\end{abstract}

\section{Internet of things Engineering Major}

In recent years, the Internet of things as a new competitive industry, has received wide attention in academia and industry and the use of a wide range, for example, in industry and living environment, etc. The Internet of things are the most representative to the number of the logistics industry, environmental monitoring, food safety and green energy saving. At present, more than 1600 enterprises in our country have been engaged in the research and manufacture of sensors, and the market scale is over 90 billion RMB. Of course, under the global scale of the Internet of things industry science and technology, the shortage of talent in the Internet of things needs to be solved.

Among the first emerging strategy majors issued by the Ministry of education, there are up to more than 700 universities reporting IOT projects, including Wuhan University, Harbin Engineering University, Hefei University of Technology and other 211 and 985 higher education institutions. The Internet of things engineering is an engineering discipline, also an interdisciplinary subject and a combination of multiple disciplines, including computer technology and science, detection and automation, and information and communication engineering.

The Internet of things is composed of the perceptual layer, the network layer and the application layer, and the following is the theoretical level of the Internet of things engineering. 
Table 1 The theoretical level of the engineering specialty of the Internet of things

\begin{tabular}{|c|c|c|}
\hline $\begin{array}{c}\text { Application } \\
\text { Theory }\end{array}$ & $\begin{array}{c}\text { The application and related fields of } \\
\text { Technology }\end{array}$ & $\begin{array}{c}\text { Domain application } \\
\text { technology }\end{array}$ \\
\hline $\begin{array}{c}\text { Professional } \\
\text { Theory }\end{array}$ & $\begin{array}{c}\text { Quantitative data management, } \\
\text { Internet of things software modeling, } \\
\text { Internet of things middleware, object } \\
\text { evolution model network, and } \\
\text { information security }\end{array}$ & Generic Technology \\
\hline Basic theory & $\begin{array}{c}\text { Internet of things architecture, } \\
\text { wireless communication, sensor } \\
\text { network }\end{array}$ & $\begin{array}{c}\text { Transmission } \\
\text { Technology }\end{array}$ \\
\cline { 2 - 3 } & $\begin{array}{c}\text { Sensor theory, RFID principle, } \\
\text { information acquisition and recognition } \\
\text { method }\end{array}$ & Perceptual Technology \\
\hline
\end{tabular}

\section{Networking engineering orientation and training objectives}

Networking engineering as an emerging industry, the prosperity and development needs of a large number of proficient in Internet information technology talents. There is also a higher requirement for the students' quality of learning the major. China networking engineering as one of the top five emerging strategic industries. The Internet of things has the characteristics of long industrial chain, and the development of the Internet of things in the contemporary era also has a great impact on the students studying this major.

1) The professional training of students' all-round development of the requirements. And have Strong computer science and technology, RF and microwave technology, system engineering theory and technology, the system can grasp things related theoretical knowledge of scientific methods and practical skills, and have the knowledge innovation in the professional field and strong ability of practice.

2) The basic idea of cultivating talents in the engineering specialty of the Internet of things is "ramming the foundation and paying attention to practice". For example, a low frequency amplifier experiment, students must remember all the possible use of the formula of Kirchhoff's law, Norton's law and so on, but also master some basic operations and methods of measurement, measurement, the AC and DC amplifier frequency; to master the use of some instruments, current meter, oscillograph, frequency meter, MV table. Only when the students master these basic principles can they finish an experiment correctly. Or, it can be said that the students are ramming the theoretical knowledge of the books through the experiment.

3) The project engineering of this major also needs teamwork spirit. To the development of software engineering as an example, the communication protocol which is very important, as well as software development tools and software testing of the basic theoretical knowledge, because the workload is very hard, the software scale and ability of single technical personnel is limited, not by a person can be done alone, at this point, we requires mutual assistance between technicians. Team cooperation has become the mainstream of the development of software engineering and logistics industry, but the professional team is not only the increase in personnel, but each task, everyone especially the division of labor (for example, calculation, analysis, management and test etc.). For example, when students are learning Protel, AUTOCAD and other basic applications, they can be divided into groups, leaders and leaders are responsible for assigning tasks, which are respectively responsible for the two parts of theory and practice. When each group completes tasks, it will discuss together

4) This major needs the creative ability of the students. Innovation is the basic requirement for every educator to students, it is also necessary to learn from the Internet in the Internet of things. For example, sensor principle and application in learning, students should not only master SSPD 
(self-scanning photodiode array) and CCD (charge coupled device) and the basic knowledge, but also understand their application in life, such as digital camera and fingerprint machine is the use of CCD, the more important is that students should learn the basic innovation. The theory will learn migration to life, invention can help simple things in life.

\section{The practice construction strategy of the Internet of things}

At present, higher education must put students' ability training in the first place. In the Internet of things, the performance is to reflect its comprehensiveness, diversity and engineering. The following are some suggestions and discussions on the practical construction strategy of the Internet of things engineering.

\subsection{Design of professional practice teaching content}

According to the technology and application of the Internet of things, the teaching model suitable for students is designed to find the educational policy of this course. For example, students who in the First grade in College, the opening of the main course of basic theory knowledge, let the students master the program design, data structure, operating system, etc.. At Second grade in College, some practical courses can be offered, such as taking students to major CNC centers or organizing their own research and development of new products. They can also get them in touch with a variety of experimental equipment. For example, the curing of the protocol stack of SNAP series, this series can help students develop thinking, SNAP network is composed of CEL and Synapse Wireless to develop a wireless mesh protocol, SNAP has many advantages, such as no networking process, to mobilize all functions without constructing a network topology, and the use of air upgrades. How to let the students understand the experimental equipment in this field can make students taste the role of practice in the study, thus arousing the enthusiasm of their learning.

\subsection{Construction of professional laboratory}

The Internet is an interdisciplinary subject, so when the school network in building course laboratory, we should fully integrate all levels of resources inside and outside schools, vigorously promote the entry of foreign enterprises into campus laboratories, and establish enterprise training labs in schools. It is a close combination of laboratories and training, to broaden students' horizons, so as to further enrich teaching methods and improve teaching environment. The Internet of things laboratory should be divided into four levels, as follows:

Table 2

\begin{tabular}{|c|c|}
\hline Basic laboratory & $\begin{array}{c}\text { The software laboratory, the data laboratory, the composition } \\
\text { principle laboratory, etc }\end{array}$ \\
\hline Professional laboratory & $\begin{array}{l}\text { RFID laboratory, wireless network technology laboratory, sensor } \\
\text { network laboratory, single-chip laboratory, embedded laboratory, } \\
\text { etc. }\end{array}$ \\
\hline Innovation Laboratory & $\begin{array}{l}\text { Intelligent home innovation laboratory and local industry } \\
\text { innovation laboratory }\end{array}$ \\
\hline $\begin{array}{l}\text { Post training } \\
\text { Laboratory }\end{array}$ & $\begin{array}{l}\text { System design architecture laboratory and Internet of things } \\
\text { system management laboratory }\end{array}$ \\
\hline
\end{tabular}

\subsection{Construction of experimental team}

The construction of the experimental team includes several aspects. The main part is the construction of the teachers' team. Every university that specializes in the engineering of the Internet of things should pay attention to the training of the scientific research and teaching ability of the teachers' team and increasing the opportunities for teachers to go out and improving the quality of the whole team of Teachers. Here are some specific methods. 


\subsubsection{Strengthening the construction of the gradient of the teaching team.}

To excavate the potential of young teachers, and to improve the ability of each teacher's time ability and theoretical accomplishment. When teachers explain some common experimental equipment, they are not only limited to the explanation of theoretical knowledge, but also should lead the students into the laboratory. For example in learning Italian semiconductor (ST) series, the students grasp their high performance and low power consumption is not enough, the Italian semiconductor using ARM Cortex and kernel composition has good compatibility and which characteristics should let the students in the laboratory experience, will strengthen the quality of students. Of course, It requires the ability of teachers' theory and practice to combining in teaching.

\subsubsection{Introducing engineering technicians from IT enterprises to improve teachers.}

No matter what is learned in books, it is not real knowledge. Introduce some IT engineers and experienced engineers to explain knowledge, so that students can have more professional knowledge. For example, when learning the MssatatePAN protocol stack, the use of the importing staff is more efficient than the traditional teacher. Because many IT companies have already introduced the equipment, most of the technicians have mastered the equipment and will be more proficient in the explanation.

\subsubsection{The alliance of enterprises and schools and the establishment of two-way mechanism.}

Schools and enterprises alliance with each other to establish a two-way mechanism of introduction and dispatch. The college should strengthen the party and school enterprise cooperation, let students and teachers in their schools have the opportunity to enter the factory training at the same time, the school also provides talents for enterprises to form a mutual win.

\section{Summary}

The Internet of things engineering is a widely developing major. At the same time, the state and society are in urgent need of this kind of professional talents. This paper focuses on strengthening the training of talents in practice construction. Practice is an effective way to consolidate theory, so universities must take the initiative to adapt to the needs of social development, pay attention to the importance of practice in professional learning, and cultivate more elites of IOT.

\section{References}

[1] Ali Li, Hailin Zhou. Construction of the practical teaching link of network engineering specialty [J]. computer education, 2011

[2] Zhongmei Ma, Juan Sun, Qi Li networking course system and practice of engineering application of MCU and embedded systems, 2013

[3] Qiang Ke, on the construction of the specialized course of the Internet of things, [J] Internet of things technology 2012 